\title{
Relationship between smoking and a new index of arterial stiffness, the cardio-ankle vascular index, in male workers: a cross-sectional study
}

\author{
Koichi Hata ${ }^{1 *}$, Toru Nakagawa ${ }^{2}$, Mitsuhito Mizuno ${ }^{1}$, Nobuaki Yanagi ${ }^{1}$, Hiroko Kitamura ${ }^{1}$, Takeshi Hayashi ${ }^{2}$,
} Masataka Irokawa ${ }^{2}$ and Akira Ogami ${ }^{1}$

\begin{abstract}
Background: Cigarette smoking is one of the major factors that increases arterial stiffness. The purpose of this study was to examine further the relationship between smoking status and arterial stiffness using a new index, the cardio-ankle vascular index (CAVI), in male Japanese workers.

Methods: This cross-sectional study included 4,729 male Japanese workers undergoing annual health checkups. CAVI was measured at the time of the annual health checkup between April 2007 and March 2008. The subjects were divided into three groups, smokers $(n=1,913)$, former smokers $(n=1,481)$ and non-smokers $(n=1,348)$ according to their responses to a questionnaire. We compared the CAVI in the three groups after adjusting for age. Multiple regression analysis was used to examine the association between CAVI and the number of cigarettes smoked per day in order to examine whether there was a dose-response relationship between smoking and CAVI.

Results: The mean CAVI for each group was $7.81 \pm 0.02$ for smokers, $7.70 \pm 0.02$ for former smokers and $7.64 \pm 0.02$ for non-smokers. A significant difference was observed between each group. According to the results of multiple regression analysis, the standardized $\beta$ of the number of cigarettes smoked per day was $0.09(p<0.01)$. This confirmed a positive association with CAVI.
\end{abstract}

Conclusions: Our study demonstrated that there is a significant association between the number of cigarettes smoked per day and arterial stiffness, as measured by CAVI.

Keywords: Cardio-ankle vascular index, Smoking, Arterial stiffness, Cardiovascular disease

\section{Background}

Cardiovascular disease is a major cause of death in industrialized countries [1]. In Japan, too, the rate of cardiovascular disease as a cause of morbidity has noticeably increased with the westernization of lifestyles. Arterial stiffening is a major factor in cardiovascular disease because of the reduced capacity in blood vessels and the concomitant rise in pulse pressure and fall in shear stress [2]. Therefore, assessment of arterial stiffness is believed to be useful in the prevention of cardiovascular disease.

\footnotetext{
*Correspondence: k-hata@med.uoeh-u.ac.jp

${ }^{1}$ Department of Work Systems and Health, Institute of Industrial Ecological Science, University of Occupational and Environmental Health, 1-1 Iseigaoka, Kitakyusyu, 811-4341 Fukuoka, Japan

Full list of author information is available at the end of the article
}

Non-invasive indices of arteriosclerosis, especially brachio-ankle pulse wave velocity (baPWV), are commonly used for measuring arterial stiffness. An association has been demonstrated between baPWV values and arteriosclerotic diseases, including cardiovascular disease [3]. However, baPWV is strongly dependent on the subject's blood pressure (BP) at the time of measurement and it is sometimes difficult to assess the baPWV value during treatment for hypertension or as a result of "white coat" hypertension. Recently, the cardio-ankle vascular index (CAVI), a new convenient method of non-invasive measurement, has been introduced to assess arterial stiffness. CAVI was developed by measuring PWV from the heart to the ankle, as well as BP [4]. CAVI represents arterial stiffness, specifically the elastic properties of the arterial wall between the aortic arch and distal arteries of the 
lower extremities. Several reports have shown that CAVI is associated with atherosclerotic disease and particularly reflects arteriosclerosis of the aorta, femoral and tibial arteries [4-6]. One of CAVI's greatest merits is that measurements remain essentially unaffected by $\mathrm{BP}$, in contrast to other non-invasive parameters of arterial stiffness [7].

Some studies in Japan suggested that chronic smoking affects arterial stiffness [8,9]. Cigarette smoking induces changes in both peripheral and central vascular function, even in young or middle aged smokers [10]. However, there are few large-scale studies on the relationship between smoking status and arterial stiffness in subjects of working age. In this cross-sectional study, we examined whether there was an association between smoking status and arterial stiffness, as measured by CAVI, and whether there was a dose-response relationship between smoking and CAVI.

\section{Methods}

\section{Subjects and methods}

Study subjects were participants in annual health examinations conducted between April 2007 and March 2008 by a Japanese electrical machinery manufacturing company who requested a CAVI assessment of arterial stiffness. CAVI examinations were performed in 4,831 male workers in a fasting state. Workers whose CAVI values were taken after a meal $(n=5)$ or were unreliable (six with ankle brachial index (ABI) $<0.9,65$ with arrhythmia [4]) or could only be measured on one side $(n=23)$, as well as any workers who declined to provide information on their smoking status $(n=3)$, were excluded from our study. Finally, a total of 4,729 subjects were selected. Written informed consent was obtained from each examinee regarding the use of his data for research purposes prior to the study. This study was approved by the ethics committee of Hitachi General Hospital.

\section{Cardio-ankle vascular index}

CAVI was measured by trained technicians using VaSera VS-1000 (Fukuda Denshi, Tokyo, Japan). Cuffs were placed bilaterally on the upper arms and ankles while the subjects were lying in a supine position with their heads held along the midline. Electrocardiography electrodes were placed on both wrists and a microphone was placed to detect heart sounds over the sternum. The participants rested in this supine position before monitoring commenced. The CAVI was calculated using the formula:

$$
\mathrm{CAVI}=2 \rho \times \ln (\mathrm{Ps} / \mathrm{Pd}) \times \mathrm{PWV} 2 / \Delta \mathrm{P}
$$

where $\mathrm{Ps}$ is systolic BP (SBP); Pd is diastolic BP (DBP); $\triangle \mathrm{P}$ is SBP-DBP;pis blood density; and PWV is pulse wave velocity. PWV was measured from the aortic valve to the ankle. Detailed CAVI measurement methods and principles have been previously reported [4]. All these measurements and calculations were performed automatically. The mean bilateral CAVI was used in our analysis. ABI was measured at the same time.

\section{Laboratory data}

Height and weight were measured using an automated scale (Tanita BF-220, Tokyo, Japan) with the participants wearing a light gown. Body mass index (BMI) was calculated as the weight in kilograms divided by the square of height in meters. Other laboratory data obtained were glycosylated hemoglobin (HbA1c), blood sugar, total cholesterol, low-density lipoprotein (LDL) cholesterol, high-density lipoprotein (HDL) cholesterol and triglycerides in the fasting state.

\section{Blood pressure measurement}

BP was measured by trained nurses with participants in the sitting position after sufficient rest. Pulse rate was measured at the same time. If SBP was over $140 \mathrm{mmHg}$ or DBP was over $90 \mathrm{mmHg}$, BP was measured again. We used the ES-H55 (Terumo, Tokyo, Japan) to measure BP.

\section{Questionnaire}

A self-administered questionnaire was used to collect information on smoking status (smoker, former smoker, non-smoker), the average number of cigarettes smoked per day (or previously smoked for former smokers), history of treatment for lifestyle diseases (diabetes mellitus, high BP, dyslipidemia) and average alcohol consumption per week. Average alcohol consumption per week was assessed by "go" in this study. A "go" is a traditional Japanese unit consisting of $23 \mathrm{~g}$ ethanol.

\section{Statistical analysis}

Statistical analysis was performed using SPSS Version 15 for Windows (SPSS, Chicago, USA). Continuous and categorical data are expressed as mean \pm standard deviation (SD) and number (percentage), respectively. A $p$-value $<0.05$ was considered statistically significant. Baseline characteristics of the participants were compared by Tukey's $t$-test. We compared the mean CAVI among the three groups: smokers, former smokers and non-smokers. However, non-invasive parameters of arterial stiffness, including CAVI, are strongly dependent on age. Therefore, data were compared as mean $\pm \mathrm{SD}$ adjusted for age by analysis of covariance (ANCOVA). In addition, multiple stepwise regression analysis was performed to examine the relation between average number of cigarettes smoked per day and CAVI. Dependent variables were 1) age; 2) BMI; 3) average number of cigarettes smoked per day; 4) SBP; 5) DBP; 6) pulse rate; 7) LDL cholesterol; 8) HDL 
cholesterol; 9) triglycerides; 10) total cholesterol; 11) HbA1c; 12) alcohol consumption (the amount of "go" consumed per week).

\section{Results}

The 4,729 subjects consisted of 1,907 smokers, 1,479 former smokers and 1,343 non-smokers. Baseline characteristics of the participants are shown in Table 1 . The average ages of non-smokers, former smokers and smokers were $48.5 \pm 8.6$ years, $51.6 \pm 7.5$ years and $48.7 \pm 8.1$ years, respectively. Former smokers were significantly older than subjects belonging to the other two groups, but there was no significant difference between smokers and nonsmokers (former smoker versus non-smoker: $p<0.01$; former smoker versus smoker: $p<0.01$; smoker versus non-smoker: $p=0.77)$. Non-smokers had significantly higher HDL-cholesterol $(p<0.01)$, SBP $(p<0.01)$ and DBP $(p<0.01)$ than smokers and significantly lower triglyceride $(p<0.01)$ and HbA1c $(p<0.01)$. Weekly alcohol

\section{Table 1 Baseline characteristics of 4,729 male Japanese workers in this study between April 2007 and March 2008, according to Smoking Status}

\begin{tabular}{|c|c|c|c|}
\hline & $\begin{array}{l}\text { Non-smoker } \\
(n=1,343)\end{array}$ & $\begin{array}{l}\text { Former smoker } \\
(n=1,479)\end{array}$ & $\begin{array}{l}\text { Smoker } \\
(n=1,907)\end{array}$ \\
\hline Age (year) & $48.5 \pm 8.6$ & $51.6 \pm 7.5^{*}$ & $48.7 \pm 8.1$ \\
\hline Body Mass Index & $24.3 \pm 3.1^{*}$ & $24.3 \pm 2.8^{*}$ & $24.0 \pm 3.2$ \\
\hline \multicolumn{4}{|l|}{ Blood pressure (mmHg) } \\
\hline Systolic & $121.5 \pm 11.5^{*}$ & $122.7 \pm 11.1^{*}$ & $118.9 \pm 12.1$ \\
\hline Diastolic & $77.8 \pm 8.0^{*}$ & $78.8 \pm 7.6^{*}$ & $76.1 \pm 8.3$ \\
\hline Pulse rate (per minute) & $68.9 \pm 10.0$ & $69.0 \pm 9.8$ & $68.2 \pm 9.1$ \\
\hline \multicolumn{4}{|c|}{ Fasting serum cholesterol (mg/dl) } \\
\hline Low-density lipoprotein & $126.0 \pm 27.7$ & $125.6 \pm 27.7$ & $124.6 \pm 30.9$ \\
\hline High-density lipoprotein & $57.0 \pm 13.7^{*}$ & $56.9 \pm 14.3^{*}$ & $52.6 \pm 13.1$ \\
\hline Triglycerides & $112.3 \pm 1.6^{*}$ & $118.1 \pm 1.7^{*}$ & $129.2 \pm 1.7$ \\
\hline Glucose (mg/dl) & $104.3 \pm 17.0$ & $108.3 \pm 22.7^{*}$ & $105.5 \pm 21.5$ \\
\hline Hemoglobin A1c (\%) & $5.4 \pm 0.6^{*}$ & $5.5 \pm 0.8$ & $5.5 \pm 0.8$ \\
\hline $\begin{array}{l}\text { Alcohol consumption } \\
\text { ("go"/week) }\end{array}$ & $3.86 \pm 4.7^{*}$ & $6.11 \pm 5.5^{*}$ & $5.91 \pm 5.9$ \\
\hline $\begin{array}{l}\text { Number of cigarettes } \\
\text { smoked per day }\end{array}$ & & $19.4 \pm 8.5$ & $19.0 \pm 6.5$ \\
\hline \multicolumn{4}{|c|}{ Under medical treatment ( $\mathrm{n}(\%)$ ) } \\
\hline High blood pressure & $150(11.2 \%)$ & $269(18.2 \%)^{*}$ & $209(11 \%)$ \\
\hline Dyslipidemia & $86(6.4 \%)$ & $155(10.5 \%)^{*}$ & $125(6.6 \%)$ \\
\hline Diabetes mellitus & $43(3.2 \%)^{*}$ & $95(6.4 \%)$ & $95(5 \%)$ \\
\hline
\end{tabular}

Values are mean \pm standard deviation or $\mathrm{n}(\%)$.

The logarithmic mean of triglycerides was examined. High blood pressure was defined as > 140/90 mmHg (Japanese Society of Hypertension: Guidelines for the Management of Hypertension 2009).

Number of cigarettes smoked per day in former smoker: Number of cigarettes smoked per day when they were smokers.

*: $p$-value $<0.05$ compared with smokers by Tukey's $t$-test or the Chi-square test. consumption was significantly lower for non-smokers than for the other two groups (non-smoker versus former smoker: $p<0.01$, non-smoker versus smoker: $p<0.01$ ).

Figure 1 shows the distribution of the average number of cigarettes smoked per day among smokers. The highest smoking frequency was an average number of 16 to 20 cigarettes per day. The frequency of more than 40 cigarettes per day was extremely low.

The CAVI data among smokers, non-smokers and exsmokers are presented in Figure 2. We used ANCOVA to adjust for the influence of age. The average CAVI of all participants was 7.73. The CAVI of smokers, exsmokers and non-smokers was $7.81 \pm 0.02,7.70 \pm 0.02$ and $7.64 \pm 0.02$, respectively. A significant difference was observed for each group (non-smoker versus former smoker: $p<0.01$, non-smoker versus smoker: $p<0.01$, former smoker versus smoker: $p=0.047$ ).

Table 2 shows the result of stepwise multiple regression analysis between non-smokers and smokers. Age was the strongest factor that affected CAVI ( $\beta$ : 0.05 , $95 \%$ confidence interval (CI) of $\beta: 0.05-0.056, p<0.01)$. After adjustment for age, the average number of cigarettes smoked per day had the greatest influence on CAVI ( $\beta$ : $0.11,95 \%$ CI of $\beta$ : 0.08-0.14, $p<0.01$ ).

\section{Discussion}

The study indicated that CAVI, the new index of arterial stiffness, differs significantly after adjustment for age in Japanese male workers, depending on their smoking status. Many studies have reported that smoking status affects the non-invasive index of arterial stiffness or arteriosclerosis $[8,9]$. In addition, previous studies showed that the average number of cigarettes smoked per day influenced arterial stiffness [11]. We were able to confirm these relationships by using CAVI, which is the new index of arterial stiffness.

Various studies have also shown that smoking plays a major role in the occurrence of arteriosclerosis and arteriosclerotic disease [12-16]. Smoking promotes arteriosclerosis because it induces nitric oxide damage to vascular endothelial cells, contributes to high $\mathrm{BP}$ or diabetes mellitus, and stimulates coagulation and fibrinolysis pathways [17]. Arterial stiffness is thought to be associated with arteriosclerosis. However, it is ethically difficult to measure arteriosclerosis by invasive methods. CAVI measures arterial stiffness noninvasively and conveniently, and this advantage makes CAVI an appropriate method for assessment of arteriosclerosis caused by smoking in working people.

The CAVI of former smokers was lower than that of smokers but higher than that of non-smokers. Smoking cessation would not result in an immediate restoration of CAVI to non-smoker levels. It was shown that it took 10-14 years after smoking cessation for the majority of 


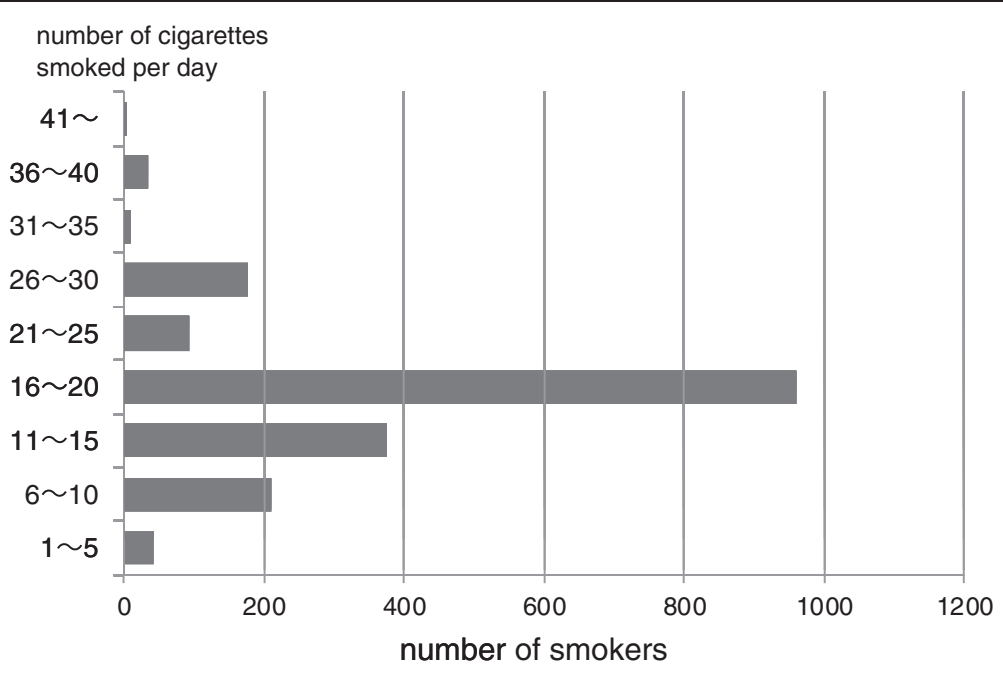

Figure 1 Smoking Frequency by number of cigarettes Smoked per day.

benefits to occur. There was no significant difference between the mortality rates of non-smokers and former smokers 10-14 years after smoking cessation [18]. Similarly, most other improvements in CAVI as a result of smoking cessation may take a long time.

The Brinkman index (the number of cigarettes smoked per day multiplied by the number of years of smoking) is commonly used to estimate the cumulative dose of smoking. In this study, however, we thought age would impact the Brinkman index and, therefore, we used the number of cigarettes smoked per day for our analysis.

Our study has several limitations. First, it is a crosssectional study. A cohort study is required to accurately assess the causal correlation. We will continue to measure the subjects' CAVI and obtain information on their smoking status at annual health checkups. Another limitation was the fact that all study subjects were male workers and thus our findings cannot be applied to women. There may be differences between men and women in CAVI due to lifestyle or disease and therefore it is necessary to conduct studies that include female subjects to determine any distinction between the genders.

\section{Conclusions}

Our study showed an association between smoking status and CAVI in Japanese male workers. CAVI was higher in smokers than in non-smokers and ex-smokers adjusted for age. In addition, the number of cigarettes

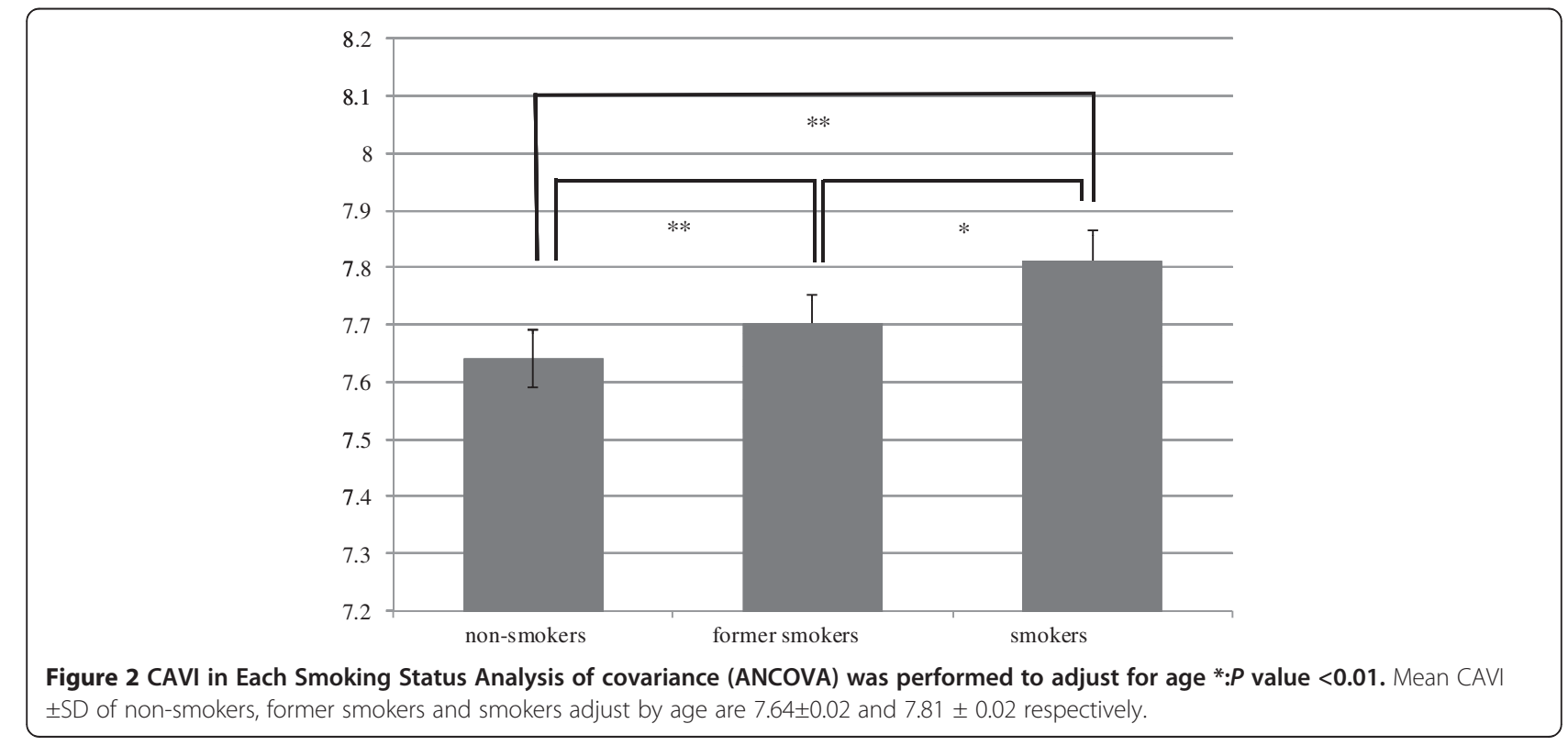


Table 2 Results of multiple linear regression analysis conducted to assess the relationship of CAVI to measures of variables in non-smoking group and smoking group $(n=3,250)$

\begin{tabular}{llll}
\hline & $\boldsymbol{\beta}$ & $\mathbf{9 5 \% C l}$ of $\boldsymbol{\beta}$ & Standardized $\boldsymbol{\beta}$ \\
\hline Age (actual age) & 0.05 & $0.05-0.056$ & 0.50 \\
Number of cigarettes smoked per day (actual number) & 0.11 & $0.08-0.14$ & 0.09 \\
R square & & & 0.45 \\
Adjusted R square & & & 0.45 \\
\hline
\end{tabular}

Dependent variables were 1) age; 2) body mass index; 3) average number of cigarettes smoked per day; 4) systolic blood pressure; 5) diastolic blood pressure; 6) pulse rate; 7) low-density lipoprotein cholesterol; 8) high-density lipoprotein cholesterol; 9) triglycerides; 10) total cholesterol; 11) HbA1c; 12) alcohol consumption (amount of "go" consumed per week). Cl, confidence interval.

Stepwise procedures were used in this analysis.

smoked per day is related to the degree of arterial stiffness, as measured by CAVI.

\section{Competing interests}

The authors declare that they have no competing interests.

\section{Authors' contributions}

$\mathrm{KH}, \mathrm{TN}$ and TH contributed to data collection. $\mathrm{KH}$ and TN contributed to data analysis. $\mathrm{KH}, \mathrm{MM}, \mathrm{HK}$, and AK interpreted the data, and wrote the manuscript. All authors read and approved the final manuscript.

\section{Acknowledgments}

This work was supported, in part, by Sompo Japan Research Institute Inc.

\section{Author details}

${ }^{1}$ Department of Work Systems and Health, Institute of Industrial Ecological Science, University of Occupational and Environmental Health, 1-1 Iseigaoka, Kitakyusyu, 811-4341 Fukuoka, Japan. ${ }^{2}$ Hitachi Health Care Center, Hitachi Ltd., 4-3-16 Osecho, Hitachi 317-0076, Ibaraki, Japan.

Received: 1 May 2012 Accepted: 16 July 2012

Published: 28 July 2012

\section{References}

1. Murray CJ, Lopez AD: Alternative projections of mortality and disability by cause 1990-2020: Global Burden of Disease Study. Lancet 1997, 349:1498-1504.

2. O'Rourke MF, Hashimoto J: Mechanical factors in arterial aging: a clinical perspective. JACC 2007, 50:1-13.

3. Kubo T, Miyata M, Minagoe S, Setoyama S, Maruyama I, Tei C: A simple oscillometric technique for determining new indices of arterial distensibility. Hypertens Res 2002, 25:351-358.

4. Shirai K, Utino J, Otsuka K, Takata M: A novel blood pressure-independent arterial wall stiffness parameter; cardio-ankle vascular index (CAVI). J Atheroscler Thromb 2006, 13:101-107.

5. Yambe T, Meng X, Hou X, Wang Q, Sekine K, Shiraishi Y, Watanabe M, Yamaguchi T, Shibata M, Kuwayama T, Murayam M, Konno S, Nitta S: Cardio-ankle vascular index (CAVI) for the monitoring of the atherosclerosis after heart transplantation. Biomed Pharmacother 2005, 59(Suppl 1):S177-S179.

6. Kadota K, Takamura N, Aoyagi K, Yamasaki H, Usa T, Nakazato M, Maeda T, Wada M, Nakashima K, Abe K, Takeshima F, Ozono Y: Availability of cardioankle vascular index (CAVI) as a screening tool for atherosclerosis. Circ $J$ 2008, 72:304-308.

7. Izuhara M, Shioji K, Kadota S, Baba O, Takeuchi Y, Uegaito T, Mutsuo S, Matsuda M: Relationship of Cardio-Ankle Vascular Index (CAVI) to Carotid and Coronary Arteriosclerosis. Circ J 2008, 72:1762-1767.

8. Yufu K, Takahashi N, Hara M, Saikawa T, Yoshimatsu H: Measurement of the brachial-ankle pulse wave velocity and flow-mediated dilatation in young, healthy smokers. Hypertens Res 2007, 30:607-612.

9. Tomiyama H, Yamazaki M, Sagawa Y, Teraoka K, Shirota T, Miyawaki Y, Yamashina A: Synergistic effect of smoking and blood pressure on augmentation index in men, but not in women. Hypertens Res 2009, 32:122-126.
10. Wiesmann F, Petersen SE, Leeson PM, Francis JM, Robson MD, Wang Q, Choudhury R, Channon KM, Neubauer S: Global impairment of brachial, carotid, and aortic vascular function in young smokers: direct quantification by high-resolution magnetic resonance imaging. J Am Coll Cardiol 2004, 44:2056-2064.

11. Virtanen MP, Koobi T, Turjanmaa VM, Majahalme S, Tuomisto MT, Nieminen T, Kahonen M: Predicting arterial stiffness with ambulatory blood pressure: an 11-year follow-up. Clin Physiol Funct Imaging 2008, 28:378-383

12. Seltzer CC: Framingham study data and "established wisdom" about cigarette smoking and coronary heart disease. JCE 1989, 42:743-750.

13. Kiyohara Y, Ueda K, Fujishima M: Smoking and Cardiovascular-Disease in the General-Population in Japan. J Hypertens 1990, 8:S9-S15.

14. Shimozato M, Nakayama T, Yokoyama T, Yoshi-ike N, Yamaguchi M, Date C: A 15.5-year cohort study on risk factors for possible myocardial infarction and sudden death within 24 hours in a rural Japanese community. J Epidemiol 1996, 6:15-22.

15. Shimamoto T, Komachi $Y$, Inada H, Doi M, Iso H, Sato S, Kitamura A, lida M, Konishi M, Nakanishi N: Trends for coronary heart disease and stroke and their risk factors in Japan. Circulation 1989, 79:503-515.

16. Konishi $M$, Iso H, lida M, Naito $Y$, Sato S, Komachi $Y$, Shimamoto T, Doi M, Ito M: Trends for coronary heart disease and its risk factors in Japan: epidemiologic and pathologic studies. Jpn Circ J 1990, 54:428-435.

17. Yanbaeva DG, Dentener MA, Creutzberg EC, Wesseling G, Wouters EF: Systemic effects of smoking. Chest 2007, 131:1557-1566.

18. Iso H, Date C, Yamamoto A, Toyoshima H, Watanabe $Y$, Kikuchi S, Koizumi A Wada Y, Kondo T, Inaba Y, Tamakoshi A: Smoking cessation and mortality from cardiovascular disease among Japanese men and women: the JACC Study. Am J Epidemiol 2005, 161:170-179.

doi:10.1186/1617-9625-10-11

Cite this article as: Hata et al:: Relationship between smoking and a new index of arterial stiffness, the cardio-ankle vascular index, in male workers: a cross-sectional study. Tobacco Induced Diseases 2012 10:11.

\section{Submit your next manuscript to BioMed Central and take full advantage of:}

- Convenient online submission

- Thorough peer review

- No space constraints or color figure charges

- Immediate publication on acceptance

- Inclusion in PubMed, CAS, Scopus and Google Scholar

- Research which is freely available for redistribution 